\title{
Early Development of the Cranial Nerves in a Primitive Vertebrate, the Sea Lamprey, Petromyzon Marinus L.
}

\author{
Antón Barreiro-Iglesias, María Pilar Gómez-López, Ramón Anadón and María Celina Rodicio*
}

\author{
Department of Cell Biology and Ecology, Faculty of Biology, University of Santiago de Compostela, 15782 Santiago de \\ Compostela, Spain
}

\begin{abstract}
The early development of the cranial nerves of the sea lamprey, Petromyzon marinus L., was studied in embryos and early prolarvae by immunocytochemical techniques with the marker for post-mitotic neurons acetylated $\alpha$ tubulin. The trigeminal and facial nerves were first observed in embryos 9 days post fertilisation. The glossopharyngeal and vagal nerves appeared later, which indicates a rostrocaudal gradient in differentiation of branchiomeric nerves. The anterior and posterior lateral line, octaval and hypoglossal nerves also appeared in early developmental stages, but the ocular motor nerves were not observed in prolarvae. The present results indicate that, in comparison with cranial nerves and ganglia organisation reported in larval and adult lampreys, organisational changes occur in the cranial nerves between the prolarval and larval stages. One important change is the disappearance of the pharyngeal branch of the facial nerve, which was not previously reported to be present in larval and adult lampreys, whereas it had been observed in earlier developmental stages. Comparison of the present results with those from studies carried out in other vertebrate species, including the Japanese lamprey, suggests that the developmental pattern of the cranial nerves is conserved in agnathans and differs from that reported in other vertebrate groups. As maturation of lamprey eyes and extraocular muscles is completed at metamorphosis, there appears to be a correlation between the late development of eye-related cranial nerves in lampreys and the anatomical structures that they innervate.
\end{abstract}

Keywords: Tubulin, agnathans, peripheral nervous system, cranial nerves, early development, whole-mount immunostaining.

\section{INTRODUCTION}

The cranial nerves in vertebrates are responsible for a variety of behaviours, including olfaction, vision, taste, balance and eye movements. The cranial nerves of the brainstem are composed of somatomotor, branchiomeric and octavolateral nerves. Branchiomeric cranial nerves innervate adjacent pharyngeal arches and show a segmental organisation, the somatomotor nerves are represented by the ocular motor nerves (oculomotor, trochlear and abducens), and the octavolateral nerves consist of the octaval and the anterior and posterior lateral line nerves. Lampreys are representatives of the most primitive group of vertebrates, the agnathans, and their phylogenetic position makes them a key group for comparative studies. The development of the early scaffold of axon tracts within the central nervous system has been previously studied in different vertebrate groups [1-8], but the early development of the cranial nerves is less studied. Development of the cranial nerves of the Pacific lamprey, Lampetra japonica, has been investigated and discussed in terms of their branchiomeric pattern [9], but it is not known whether their development is the same in other species of lamprey in the Atlantic Ocean. Even though the two genera, Petromyzon and Lampetra, show many morphological and physiological similarities, a few differences remain $[10,11]$. In addition, in south Europe and North America, $P$. marinus is more easily accessible and some groups of

*Address correspondence to this author at the Department of Cell Biology and Ecology, Faculty of Biology, University of Santiago de Compostela, 15782 Santiago de Compostela, Spain; Tel: 00349815631 00, Ext: 16946; Fax: 981 596904; E-mail: mcelina.rodicio@usc.es scientists study the lamprey nervous system using $P$. marinus as a model [12-20], but cranial nerve anatomical data in the early developmental stages of this species are lacking. In spite of the previous study on the Pacific lamprey, a comparative analysis between the early development of cranial nerves in lampreys and in other vertebrates has not yet been carried out. In the present study, we analysed the development of the cranial nerves in the sea lamprey, using antibodies against acetylated $\alpha$-tubulin, a neuronal marker used in developmental studies in lamprey [8, 9, 21] and teleosts $[1,6]$. The main objectives of the study were 1) to compare the results for lamprey with those reported for other vertebrates, to determine the degree of conservation of developmental patterns in evolution and 2) to analyse the degree of conservation of cranial nerve development between lampreys belonging to different genera. In addition, since the organisation of the cranial nerves in the larval and adult sea lamprey has previously been studied in detail [22-24], the present results also allowed comparison of the organisation of the cranial nerves in embryonic/early prolarval sea lamprey stages and larvae.

\section{MATERIALS AND METHODOLOGY}

\section{Animals}

Embryos and prolarvae were obtained from in vitro fertilised eggs, which were taken from sexually mature adult sea lampreys caught in the River Ulla (north-western Spain). Fertilised eggs were reared in the laboratory under appropriate conditions of darkness and temperature [25]. The stages of embryos (E) and prolarvae (P) are indicated by days from fertilisation and hatching, respectively. Late embryos (E8- 
E12, $\mathrm{n}=15)$ and prolarvae $(\mathrm{P} 0-\mathrm{P} 7 ; \mathrm{n}=19)$ of sea lamprey $(P$. marinus L.) were used. For group prolarvae, we adopted Piavis' stages of sea lamprey development [26]: hatchling (P0-P1), pigmentation (P2-P3), gill-cleft (P4-P7) and burrowing (P8-P23). The experiments complied with European Union regulations on animal care and experimentation.

\section{Tubulin Immunohistochemistry}

Embryos and prolarvae were fixed in $4 \%$ paraformaldehyde in $0.1 \mathrm{M}$ phosphate buffer $(\mathrm{pH}$ 7.4) for $5 \mathrm{~h}$, washed in Tris- $\mathrm{HCl}(0.05 \mathrm{M}, \mathrm{pH} 7.4)$, dehydrated in methanol and stored at $-20^{\circ} \mathrm{C}$ in methanol. For whole-mount immunostaining, samples were incubated with proteinase K (Sigma, St. Louis, MO; $30 \mu \mathrm{g} / \mathrm{ml}$ in Tris- $\mathrm{HCl}$ ) for $1-3 \mathrm{~h}$ at room temperature and with acetone at $-20^{\circ} \mathrm{C}$ for $7 \mathrm{~min}$. The samples were then pretreated with $5 \% \mathrm{H}_{2} \mathrm{O}_{2}$ in Tris- $\mathrm{HCl}$ to block endogenous peroxidases before incubation in the monoclonal antiacetylated $\alpha$-tubulin antibody (Sigma; dilution 1:500). Antibody dilutions were made in Tris- $\mathrm{HCl}$ containing $2.92 \%$ $\mathrm{NaCl}, 0.5 \%$ Triton $\mathrm{X}-100$ and $1 \%$ dimethyl sulfoxide under agitation for 5 to 6 days. After the incubation with the antitubulin antibody, the samples were incubated first with goat anti-mouse immunoglobulin G (Dako, Golstrup, Denmark; dilution 1:50) overnight, and then with mouse peroxidaseantiperoxidase complex (Sigma) for $24 \mathrm{~h}$. The immunoreac-

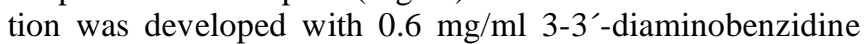
(Sigma) and $0.003 \% \mathrm{H}_{2} \mathrm{O}_{2}$ for $40-70 \mathrm{~min}$. Samples were rinsed and cleared in a mixture of glycerol and water (1:1). Embryos and prolarvae were mounted on concavity well glass slides for observation with an Olympus BX51 microscope. Photomicrographs were taken with Olympus DP12 and Olympus DP70 digital cameras. Photomicrographs were adjusted for brightness and contrast with Corel Draw 12 software.

\section{Tubulin Immunofluorescence}

For immunofluorescence, samples were prepared as above, except that the primary antibody was diluted in a ratio of 1:250. The secondary antibody was FITC-coupled goat anti-mouse (Chemicon, Temecula, CA; diluted 1:50), for a 1 $\mathrm{h}$ exposure. The antibody dilutions were carried out in TBS containing $15 \%$ normal goat serum and $0.2 \%$ Triton X-100. Photomicrographs were taken with a spectral confocal laser microscope (Leica TCS-SP2). The photomicrographs were converted to gray scale, inverted and adjusted for brightness and contrast using the Adobe Photoshop software.

\section{Histology}

After tubulin immunostaining, some samples were cryoprotected in $30 \%$ sucrose containing $0.01 \%$ of sodium azide, embedded in Tissue Tek (Sakura), frozen, cut on a cryostat (40 $\mu \mathrm{m}$ thick), mounted on gelatin-subbed slides and observed and photographed as above. For the immunofluorescence experiments, the sections were coverslipped with Vectashield (Vector Laboratories, Burlingame, CA).

\section{Controls}

The primary anti-tubulin antibody [27] has previously been shown to label early differentiated neurons and their processes in the embryonic nervous system $[1,6,8]$. As a control, the primary antibody was omitted from some samples; these samples did not show any staining. Since present procedures specifically reveal early axons, no further controls were included.

\section{RESULTS}

The organisation of the cranial nerves in a sea lamprey P5 prolarvae is shown in Fig. (1). The sequential development of these nerves is presented in the series of photos in Fig. (2). The nomenclature for cranial nerves used here follows that of [9].

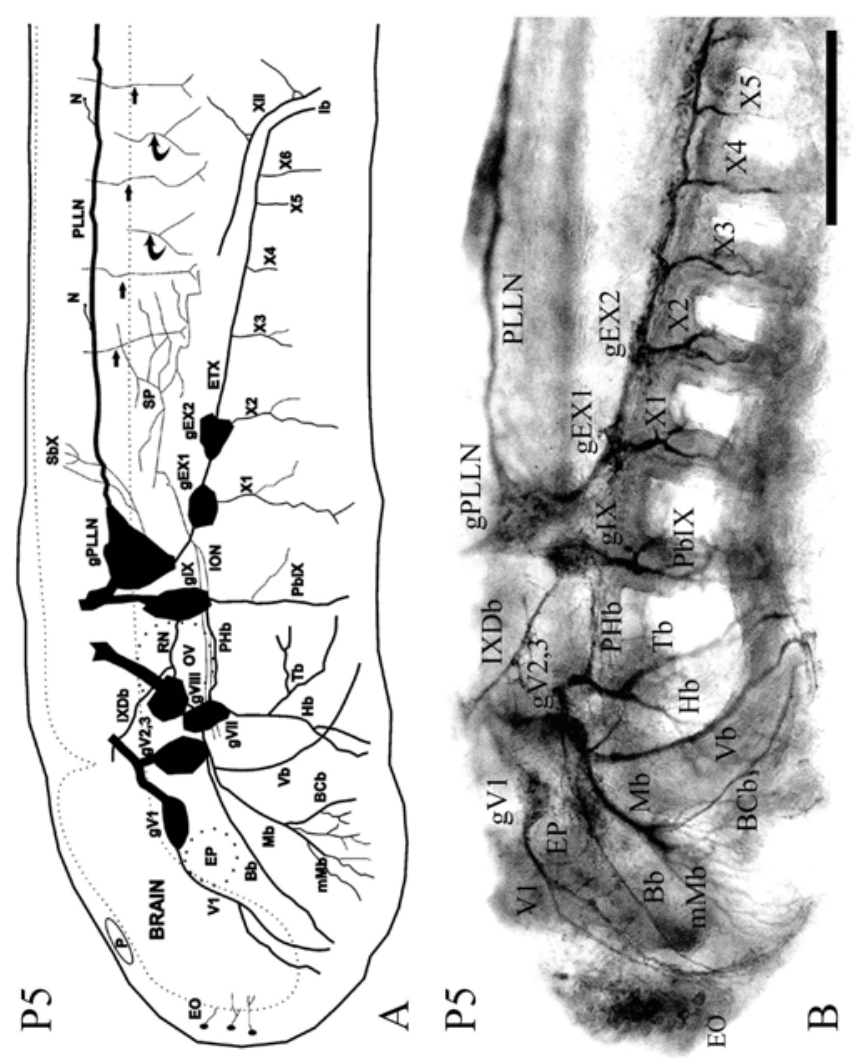

Fig. (1). Organisation of the sea lamprey cranial nerves in a P5 prolarva. A: Schematic drawing showing the organisation of the cranial nerves in a P5 prolarva. The dotted line indicates the brain. $\mathrm{Bb}$ : Buccal branch, BCb: Buccinator branch, EO: Ectopic olfactory cells, EP: Eye primordium, ETX: Epibranchial tract of the vagal nerve, gV1-gPLLN: Ganglia of the different nerves, Hb: Hyomandibular branch, Ib: Intestinal branch, ION: Infraoptic nerve, IXDb: Dorsal branch of the IX nerve, Mb: Maxillary branch, mMb: Medial maxillary branch, N: Neuromast, OV: Otic vesicle, P: Pineal, PbIX: Principal branch of the IX nerve, PHb: Pharyngeal branch, PLLN: Posterior lateral line nerve, $\mathrm{Rb} / \mathrm{RN}$ : Recurrent branch/nerve, SbX: Sensory branch of the vagal nerve, SP: Spinal plexus, Tb: Thyroid branch, V1: Deep ophthalmic nerve, Vb: Velar branch, X1X6: Epibranchial branches, XII: Hypoglossal nerve. Black arrows indicate the ventral spinal roots. Curved arrows indicate the dorsal spinal roots. B: Lateral view of a P5 prolarva showing the organissation of the cranial nerves at this developmental stage. Abbreviations as in A. Scale bar: $100 \mathrm{~mm}$. Rostral is at the left in all the figures.

Olfactory ectopic cells are present in E9 embryos just rostral to the brain, and send processes towards the forebrain. At this stage, the primordium of the trigeminal (V) nerve (Fig. 2A) is formed by one root that splits in two branches in 
the periphery after brain exit (Fig. 2A). These fibers are originated from dorsal cells (Fig. 2C and 2D) of the caudal rhombencephalon and spinal cord [8]. In addition, the facial (VII) nerve primordium is observed (Fig. 2A and 2B). At this stage, dorsal spinal roots, but no spinal ganglia, become appreciable between adjacent myotomes, and split into two branches coursing to the skin. In E11 embryos, the otic vesicle is clearly visible at the level of the VII nerve. At this stage, the primordium of the posterior lateral line nerve (PLLN) courses caudally under the epidermis, parallel to the dorsolateral longitudinal fascicle of the spinal cord (Fig. 2C).

The four most rostral pharyngeal pouches are observed for the first time in P1 prolarvae. The ventral (motor) spinal roots are first observed in these prolarvae coursing to the middle of the adjacent myotomes (Fig. 2D). At this stage, the distinction of the deep ophthalmic (V1) from the maxillomandibular (V2,3) nerves is clearer than in earlier stages. The V2, 3 nerve courses just in front of the first pharyngeal pouch. The motor root of the VII nerve emerges at the level of the otic vesicle and courses dorsorostral and medial to it. The ventral peripheral branch of the glossopharyngeal nerve (IX) emerges caudal to the otic vesicle and at the level of the third pharyngeal pouch (Fig. 2E). At this stage, the epibranchial tract of the vagal cranial nerve (X) also appears (Fig. 2E), the principal trunk of which courses between myotomes 2 and 3. The PLLN enters the rhombencephalon between the entries of the IX and X cranial nerves.

The cranial nerves are more profusely branched in P3 prolarvae. The V1 nerve reaches the region near the olfactory epithelium, whereas the two branches of the V2,3 nerve are observed for the first time: the velar and maxillary branches. The V1 and V2,3 ganglia of the V nerve become distinguishable (Fig. 2F). The VII nerve develops the buccal branch (Fig. 2F) and its principal branch, the hyomandibular nerve. At this stage, a new branch of the IX nerve, the dorsal branch, appears (Fig. 2G). The epibranchial tract of the $\mathrm{X}$ nerve is more developed than at earlier stages and the first posttrematic vagal branch appears coursing in a ventral direction.

In P5 prolarvae, the cranial nerves show a rich ramification and the cranial nerve ganglia become conspicuous (Fig. 1 and $\mathbf{2 I}-\mathbf{L}$ ):

\section{Nerve}

Two trigeminal ganglia are present, one dorsorostral (V1) and the other ventromedial (V2,3). Since the V1 and V2,3 nerves and their ganglia are separated in embryos and early prolarval stages, it appears appropriate to refer to them independently. The V1 nerve courses rostroventrally, dorsal to the eye primordium and distally divides into two branches, whereas the V2,3 nerve presents two branches: the maxillary branch which innervates the anterior buccal muscle and the superior lip, and the velar branch for the velum (Figs. 1B and 2K). The maxillary branch in turn divides into the medial and the buccinator branches (Fig. 1B). The V1 and the V2,3 ganglia give rise to distinct central branches that, after branching, enter the rhombencephalon by its rostral region.

\section{Nerve}

The ganglion of the VII nerve forms the most rostroventral portion of the facial-octaval ganglionic complex
(VII/VIII). This nerve presents four branches: 1) the buccal branch courses rostrally, ventral to the eye primordium; 2) the hyomandibular branch innervates the inferior lip; 3) the thyroid branch follows a caudal trajectory in the pharyngeal floor, and 4) the pharyngeal branch passes near the ventral region of the otic vesicle in its caudal course (Fig. 2B). The central root of the VII nerve (Fig. 2I) enters the rhombencephalon at the same level as the VII motor root.

\section{Nerve}

The ganglion of the octaval nerve (VIII) forms the dorsocaudal portion of the VII/VIII ganglionic complex (Fig. 2I). The VIII nerve enters the rhombencephalon at the level of the otic vesicle, dorsal to the sensory root of the VII nerve.

\section{Nerve}

The IX ganglion is located caudal to the otic vesicle and rostral and ventral to the PLLN ganglion (Figs. 1B, 2I and 2K). The peripheral part of the IX nerve splits into two branches: the ventral branch (pharyngeal branch) courses at the level of the third pharyngeal pouch to reach the ventral surface of the head and the dorsal branch courses away from the otic vesicle and lateral to the recurrent branch of the anterior lateral line nerve (ALLN), reaching the dorsal surface of the head (Fig. 2K).

\section{$X$ Nerve (Figs. $1 B$ and $2 K$ )}

In P5 prolarvae, the $X$ nerve shows two epibranchial ganglia situated dorsal to pharyngeal pouches 4 and 5, respectively. The $\mathrm{X}$ nerve presents a proximal root, and a ventral branch, the epibranchial tract of the $\mathrm{X}$ nerve. The proximal root courses to the rhombencephalon at the level of the ganglion of PLLN. The epibranchial tract courses over the pharyngeal pouches and under the myotomes and successively gives rise to six ventral branches that course in the branchial arches situated between pharyngeal pouches 3 to 8 , with the two rostralmost branches being more developed. At this stage of development, the primordium of the intestinal branch extends from the caudal part of the epibranchial tract. The proximal root leaves the ganglion diverging in a fan shape and enters the caudal part of the rhombencephalon.

\section{Lateral Line Nerves}

The primordium of the ALLN ganglion is situated ventromedial to the otic vesicle. Although the presence of the VII ganglion lateral to the ALLN ganglion makes visualisation of this ALLN ganglion difficult, one of the ALLN branches, the recurrent branch, which interconnects the VII ganglion and the dorsal root of the IX nerve (Fig. 2I), is observed in our P5 prolarva.

The PLLN ganglion is situated dorsocaudal to the IX ganglion (Figs. 1B and 2K). The central PLLN root follows a dorsorostral route to its entry in the rhombencephalon. The peripheral part of this nerve extends caudally along the upper body, and its small branches contact the neuromasts situated over the branchial region, and along the trunk and the tail (Fig. 2H).

\section{Hypoglossal Nerve (XII)}

At this stage, the XII nerve appears and is situated dorsal and caudal to the epibranchial tract (Fig. 2L). This nerve extends caudoventral to the pharynx. 


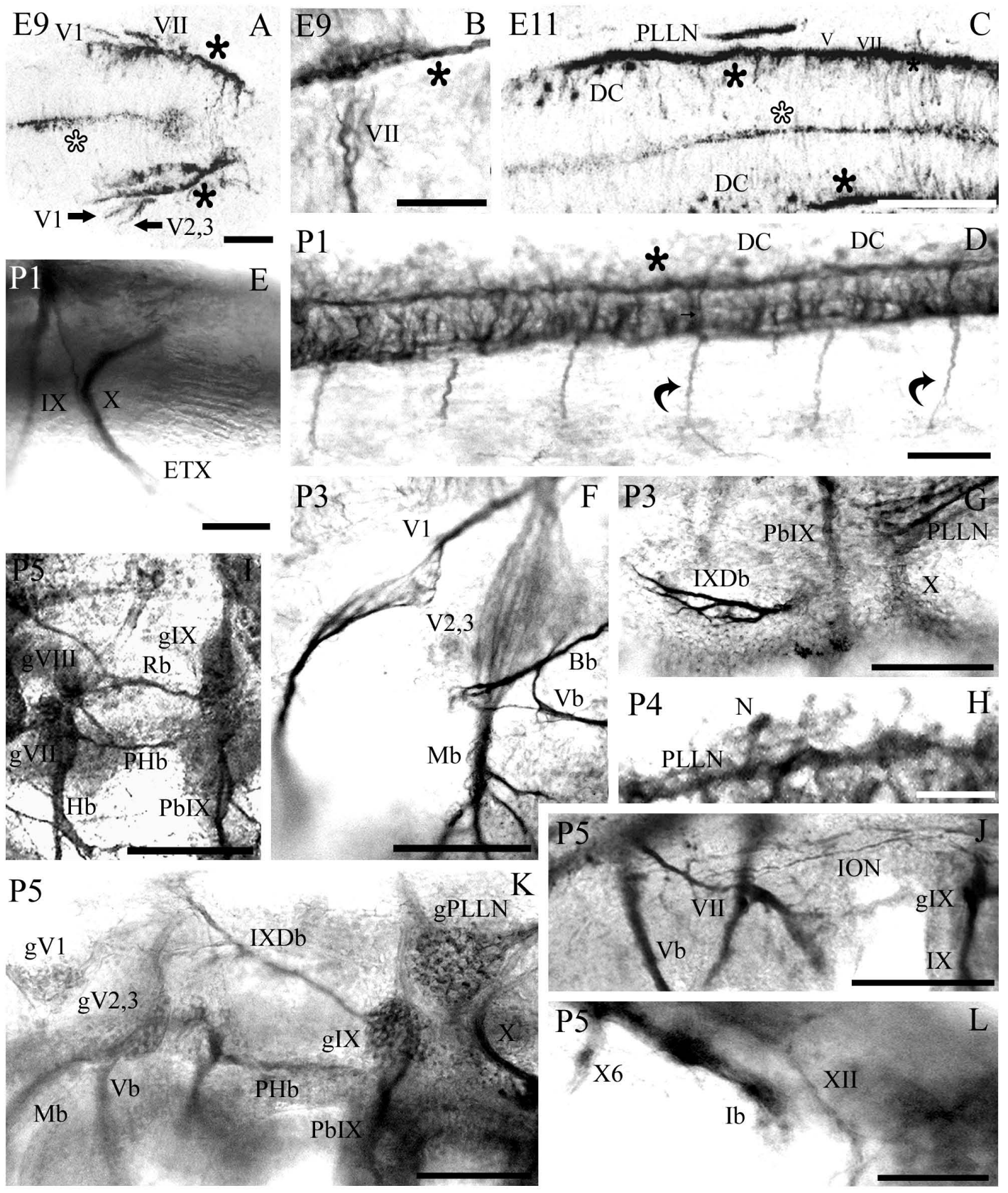

Fig. (2). Early development of the sea lamprey cranial nerves. A: Detail of the V and VII nerve primordia in an E9 embryo. Note at the bottom (black arrows) that it is possible to observe the presence of the two branches of the $\mathrm{V}$ nerve. The black asterisks indicate the dorsolateral fascicles of the brain. The white asterisk indicates the medial line of the brain. B: The VII nerve primordium in an E9 embryo. C: Detail of the PLLN primordium in an E11 embryo. DC: Dorsal cells. D: Photomicrograph showing the spinal nerves of a P1 prolarva. Curved arrow indicates a dorsal spinal root. E: Photomicrograph showing the X nerve in a P1 prolarva. F: Detail of the trigeminal branches in a P3 prolarva. G: Photomicrograph showing the dorsal branch of the IX nerve in a P3 prolarva. H: Detail of a neuromast innervated by a small branch of the PLLN in a P4 prolarva. I: Detail of the recurrent nerve/branch of the ALLN in a P5 prolarva. J: Photomicrograph showing the presence of the ION in a P5 prolarva. K: Photomicrograph showing the central projections of the cranial nerve ganglia in a P5 prolarva. L: Detail of the XII nerve primordium in a P5 prolarva. Abbreviations as in Fig. (1A). Scale bars: $25 \mathrm{~mm}$ in A, $50 \mathrm{~mm}$ in B-L. Figs. (B, D-G and $\mathbf{J}-\mathbf{L}$ ) are lateral views of whole mounted samples, Fig. (A) is a dorsal view of a whole mounted embryo, Fig. (C) is a horizontal section and Fig. (H) is a sagittal section. Rostral is at the left in all the figures. Figs. (A) and (C) correspond to tubulin immunofluorescence experiments.

\section{Ventral Spinal Nerves}

A plexus arises from the rostral ventral spinal nerves, and is located caudal to the PLLN ganglion. Its branches are slight. A rostrally extending branch of this plexus, the in- fraoptic nerve, courses ventral to the eye primordium and innervates myotomes 1 to 3 (Fig. 2J).

In $\mathrm{P} 7$ prolarvae, no new branches of the cranial nerves appear. 


\section{DISCUSSION}

The early development of the cranial nerves of the sea lamprey, Petromyzon marinus, is shown for the first time. Comparison between the present results in sea lamprey and those reported in Lampetra japonica $[9,21]$ showed that the initial pattern of development of the cranial nerves in the two lamprey species is similar. The differences observed are related to the relative time and/or degree of development of the nerves at specific stages. A comparison between the stages of development of P. marinus and L. japonica is shown in Table 1. The cranial nerves are less well-developed in P5-P7 sea lamprey prolarvae than in stage 28 of L. japonica. Unlike in $L$. japonica, in sea lamprey prolarvae, no fibres are detected in the optic nerve primordium, although differentiation of first photoreceptors has begun [28]. Previous results indicate that retinopetal fibres reach the retina at later prolarval stages [28]. The rostral spinal plexus is also less well developed in P5-P7 Petromyzon, and the supraoptic nerve that innervates myotomes 1 to 3 has not appeared at this stage. In the same way, the branchial branches of the $\mathrm{X}$ nerve are also less well developed, principally the caudal branches.

Studies have been carried out on made of the early development of cranial nerves and ganglia in other vertebrate species. In medaka embryos, the $\mathrm{V}$ ganglion was reported to appear at stage 23 , and shortly after, those of the oculomotor (III), V and VII cranial nerves (at stage 26) [7]. In sturgeon, a primitive bony fish, the origin of $\mathrm{V} 1$ and $\mathrm{V} 2 / 3$ nerves is early but distinct, although their ganglia merge at later stages, followed by the subsequent appearance of the IX, VII, X and ALL nerves [29]. In the cat shark Scyliorhinus torazame [30], the first nerves to appear were the $\mathrm{V}$ nerve with the two principal branches (at stage I), followed by the III, VII+VIII, IX and X nerves at stage IV. The early development of the III, IV, V, VII, VIII and lateral line nerves was reported in Amblystoma embryos [31-33]. The first fibres of the optic nerve [34], the $\mathrm{V}$ nerve [35] and lateral line nerves were observed in embryos of Xenopus [36]. In chick embryos, the early development of the V [37], IX and X cranial nerves [38] was also reported. In mouse embryos, the VII and IX ganglia appeared at 9 days post fertilization (dpf), the $\mathrm{V}$ ganglion and the III and IV nerves at $9.5 \mathrm{dpf}$ and the $\mathrm{X}$ ganglion at $10 \mathrm{dpf}[3,39]$. Comparison of these data with the present results indicate that the independent origin of two branches of the V nerve, the V1 and V2/V3 branches are a shared characteristic in lampreys and sturgeon, whereas the $\mathrm{V}$ nerve has a single origin in sharks, teleosts, amphibians and mammals. The VII nerve of lampreys differs from that of gnathostomes in the absence of an internal mandibular branch, the innervation of the correspondent region is by nerve V [40, present results]. The V, VII, IX and X nerves appear to develop very early in all the vertebrates studied including the sea lamprey (present results). The lateral line nerves develop early in other aquatic vertebrates as in the sea lamprey (present results). The early appearance of hypoglossal nerve fibres was reported both in frogs [41], chicks [38, 42] rats [43] and humans [44] as occur in lampreys [9, present results].

The optic nerve and the ocular motor nerves (III, IV and VI) were not observed in the sea lamprey stages here studied, they appear much later in sea lamprey than in other vertebrates. The late development of the eye-related nerves in lamprey appears to be correlated with the late development of the eye. This may be because maturation of eyes and eye muscles is delayed until metamorphosis, which occurs several years after hatching [45]. Even, the larval lamprey eye is underdeveloped and probably acts only as an ocellus [46].

Comparison between previously reported results in older lampreys [22-24, 47] and present observations in early developmental stages of the sea lamprey indicates that some reorganisation of cranial nerves occurs between embryonic/early prolarval and larval/adult stages. This involves fusion of previously separated ganglia, changes in the relative positions of ganglia and nerve branches, formation of new branches and disappearance of early branches.

The two V ganglia present in prolarvae merge into a single ganglion in larvae and adults, although partial subdivision of this ganglion denotes its dual origin [22, 24]. The prolarval VII ganglion is situated rostral to the otic vesicle, whereas in larval and adult lampreys, it becomes included in the cartilaginous otic capsule, to form the rostral portion of the VII/VIII ganglionic complex [48]. The VII nerve pre-

Table 1. The Table Compares the Developmental Stages of Lampetra and Petromyzon [Modified from 9]. The Days of Development in the Third Column are after Fertilisation in Embryos (E) and Post-Hatching in Prolarvae (P)

\begin{tabular}{|c|c|c|}
\hline Lampetra reissneri [49] & P. marinus [26] & Days of development (P.marinus) \\
\hline \hline Stage 21 & 12 & E6-E8 \\
\hline Stage 22 & 13 & E8-E12 \\
\hline Stage 23 & 13 & E8-E12 P0-P1 \\
\hline Stage 24 & $13-14$ & P1 \\
\hline Stage 25 & 14 & P2-P3 \\
\hline Stage 26 & 15 & P3 \\
\hline Stage 27 & 15 & P4-P7 \\
\hline Stage 28 & 16 & Days 33 to 40 \\
\hline Stage 29 & 18 & \\
\hline
\end{tabular}


sents four branches in the prolarvae (buccal, thyroid, hyomandibular and pharyngeal), whereas larvae show only three branches: buccal, ophthalmic superficial and hyomandibular. The pharyngeal branch was described previously in gnathostomes but is absent in larval and adult lampreys [22]. Its presence in lamprey prolarvae suggests that it represents a primitive character shared with jawed vertebrates.

The IX ganglion is rostral to the ganglion of the posterior lateral line nerve in prolarvae whereas it is caudal to the ganglion in larvae and adults, though its peripheral branches remain similar $[22,23]$.The $\mathrm{X}$ nerve presents two peripheral branches in larval specimens: one runs from the lateral region of the ganglion in a ventrocaudal direction with respect to the otic vesicle and then turns in a dorsal direction. The other branch runs from the ventral region of the ganglion caudally to the branchial region where it divides into three fascicles $[22,23]$. By contrast, dorsal, epibranchial and intestinal branches are observed in prolarvae. In the larvae, the PLLN ganglion forms the dorsorostral portion of the metaotic complex, which also contains the $\mathrm{X}$ ganglion and the ALLN ganglion [22, 23]; in the prolarvae, by contrast, this ganglion is situated dorso-caudally with respect to the IX ganglion. There is therefore positional reorganisation as well as fusion of ganglia during development.

\section{CONCLUSIONS}

The developmental pattern of the cranial nerves is very similar in Petromyzon and Lampetra, which suggests that this pattern is highly conserved in lampreys. The delayed development of the optic ocular motor nerves observed in lampreys compared to in jawed vertebrates appears to be related to the prolonged blind larval stage of lampreys. Important changes occur in the organisation of cranial nerves between the embryonic/early prolarval and larval/adult stages of the sea lamprey, involving changes in the position of the ganglia and remodelling of some nerve branches.

\section{ACKNOWLEDGEMENTS}

This work was supported by Xunta de Galicia (PGIDIT04PXIDI20003PR), and a predoctoral contract (María Barbeito contract) from the Xunta de Galicia to A. Barreiro-Iglesias.

\section{REFERENCES}

[1] Chitnis AB, Kuwada JY. Axonogenesis in the brain of zebrafish embryos. J Neurosci 1990; 10: 1892-1905.

[2] Ross LS, Parrett T Jr. Easter SS. Axonogenesis and morphogenesis in the embryonic zebrafish brain. J Neurosci 1992; 12: 457-82.

[3] Mastick GS, Easter SS. Initial organization of neurons and tracts in the embryonic mouse fore- and midbrain. Dev Biol 1996; 173: 7994.

[4] Mastick GS, Davis NM, Andrew GL, Easter SS Jr. Pax-6 functions in boundary formation and axon guidance in the embryonic mouse forebrain. Development 1997; 124: 1985-97.

[5] Anderson RB, Key B. Novel guidance cues during neuronal pathfinding in the early scaffold of axon tracts in the rostral brain. Development 1999; 126: 1859-68.

[6] Doldán MJ, Prego B, Holmqvist B, Helvik JV, de Miguel E. Emergence of axonal tracts in the developing brain of the turbot (Psetta maxima). Brain Behav Evol 2000; 56: 300-9.

[7] Ishikawa Y, Kage T, Yamamoto N, et al. Axonogenesis in the medaka embryonic brain. J Comp Neurol 2004; 476: 240-53.

[8] Barreiro-Iglesias A, Villar-Cheda B, Abalo XM, Anadón R, Rodicio MC. The early scaffold of axon tracts in the brain of a primitive vertebrate, the sea lamprey. Brain Res Bull 2008; 75: 42-52.
[9] Kuratani S, Ueki T, Aizawa S, Hirano S. Peripheral development of cranial nerves in a cyclostome, Lampetra japonica: Morphological distribution of nerve branches and the vertebrate body plan. J Comp Neurol 1997; 384: 483-500.

[10] Hardisty MW, Potter IC. The general biology of adult lampreys. In: Hardisty MW, Potter IC, Eds. The Biology of Lampreys, vol. 1. London: Academic Press 1971; 127-206.

[11] Potter IC, Hilliard RW, Bird DJ. The stages in metamorphosis. In: Hardisty MW, Potter IC, Eds. The Biology of Lampreys, vol. 1. London: Academic Press 1982; 137-165.

[12] Zhang L, McClellan AD. Axonal regeneration of descending brain neurons in larval lamprey demonstrated by retrograde double labeling. J Comp Neurol 1999; 410: 612-26.

[13] Del Carmen De Andres M, Anadon R, Manso MJ, Gonzalez MJ. Distribution of thyrotropin-releasing hormone immunoreactivity in the brain of larval and adult sea lampreys, Petromyzon marinus L. J Comp Neurol 2002; 453: 323-35.

[14] Cohen AH, Abdelnabi M, Guan L, Ottinger MA, Chakrabarti L. Changes in distribution of serotonin induced by spinal injury in larval lampreys: evidence from immunohistochemistry and HPLC. J Neurotrauma 2005; 22: 172-88.

[15] Pombal MA, Lopez JM, de Arriba MC, Megias M, Gonzalez A. Distribution of neuropeptide FF-like immunoreactive structures in the lamprey central nervous system and its relation to catecholaminergic neuronal structures. Peptides 2006; 27: 1054-72.

[16] Osorio J, Megias M, Pombal MA, Retaux S. Dynamic expression of the LIM-homeodomain gene Lhx15 through larval brain development of the sea lamprey (Petromyzon marinus). Gene Expr Patterns 2006; 6: 873-78.

[17] Shifman MI, Selzer ME. Semaphorins and their receptors in lamprey CNS: Cloning, phylogenetic analysis, and developmental changes during metamorphosis. J Comp Neurol 2006; 497: 115-32.

[18] Laframboise AJ, Ren X, Chang S, Dubuc R, Zielinski BS. Olfactory sensory neurons in the sea lamprey display polymorphisms. Neurosci Lett 2007; 414: 277-81.

[19] Parker D, Gilbey T. Developmental differences in neuromodulation and synaptic properties in the lamprey spinal cord. Neuroscience 2007; 145: 142-52.

[20] Villar-Cerviño V, Barreiro-Iglesias A, Anadón R, Rodicio MC. Distribution of glycine immunoreactivity in the brain of adult sea lamprey (Petromyzon marinus). Comparison with gammaaminobutyric acid. J Comp Neurol 2008; 507: 1441-63.

[21] Kuratani S, Horigome N, Ueki T, Aizawa S, Hirano S. Stereotyped axonal bundle formation and neuromeric patterns in embryos of a cyclostome, Lampetra japonica. J Comp Neurol 1998; 391: 99. 114.

[22] Johnston JB. The cranial nerve components of Petromyzon. J Morph 1905; 34: 149-203.

[23] Johnston JB. Additional notes on the cranial nerves of Petromyzonts. J Comp Neurol 1908; 18: 569-608.

[24] Lindström T. On the cranial nerves of the cyclostomes with special reference to the N. trigeminus. Acta Zool Stockh 1949; 30: 316458.

[25] Rodríguez-Muñoz R, Nicieza AG, Braña F. Effects of temperature on developmental performance, survival and growth of sea lamprey embryos. J Fish Biol 2001; 58: 475-86.

[26] Piavis GW. Embryology. In: Hardisty MW, Potter IC, Eds. The Biology of Lampreys, vol 1. London: Academic Press 1971; 361400.

[27] Piperno G, Fuller MT. Monoclonal antibodies specific for an acetylated form of alpha-tubulin recognize the antigen in cilia and flagella from a variety of organisms. J Cell Biol 1985; 10: 2085-94.

[28] Meléndez-Ferro M, Pérez-Costas E, Villar-Cheda B, et al. Early development of the retina and pineal complex in the sea lamprey: comparative immunocytochemical study. J Comp Neurol 2002; 442: 250-65.

[29] Kuratani S, Nobusada Y, Saito H, Shigetani Y. Morphological characteristics of the developing cranial nerves and mesodermal head cavities in sturgeon embryos from early pharyngula to late larval stages. Zool Sci 2000; 17: 911-33.

[30] Kuratani S, Horigome N. Developmental morphology of branchiomeric nerves in a cat shark, Scyliorhinus torazame, with special reference to rhombomeres, cephalic mesoderm, and distribution patterns of cephalic crest cells. Zool Sci 2000; 17: 893-909.

[31] Herrick CJ. Development of the brain of Amblyostoma in early functional stages. J Comp Neurol 1937; 67: 381-422. 
[32] Herrick CJ. Development of the cerebrum of Amblyostoma during early swimming stages. J Comp Neurol 1938; 68: 203-41.

[33] Northcutt RG, Brändle K. Development of branchiomeric and lateral line nerves in the axolotl. J Comp Neurol 1995; 355: 427-54.

[34] Cima C, Grant P. Development of the optic nerve in Xenopus laevis. I. Early development and organization. J Embryol Exp Morphol 1982; 72: 225-49.

[35] Davies SN, Kitson DL, Roberts A. The development of the peripheral trigeminal innervation in Xenopus embryos. J Embryol Exp Morphol 1982; 70: 215-24.

[36] Winklbauer R. Development of the lateral line system in Xenopus. Prog Neurobiol 1989; 32: 181-206.

[37] Kuratani S, Tanaka S. Peripheral development of avian trigeminal nerves. Am J Anat 1990; 187: 65-80.

[38] Kuratani SC, Miyagawa-Tomita S, Kirby ML. Development of cranial nerves in the chick embryo with special reference to the alterations of cardiac branches after ablation of the cardiac neural crest. Anat Embryol 1991; 183: 501-14.

[39] Easter SS, Ross LS, Frankfurter A. Initial tract formation in the mouse brain. J Neurosci 1993; 13: 285-99.

[40] Marinelli W, Strenger A. Vergleichende anatomie und morphologie der wirbeltiere, life Lampetra fluviatilis (L.). Wien: franz Deuticke 1954; 1: 1-80.

[41] Schlosser G, Roth G. Evolution of nerve development in frogs. I. The development of the peripheral nervous system in Discoglossus pictus (Discoglossidae). Brain Behav Evol 1997; 50: 61-93.
[42] Kuratani S, Tanaka S, Ishikawa Y, Zukeran C. Early development of the hypoglossal nerve in the chick embryo as observed by the whole-mount nerve staining method. Am J Anat 1988; 182: 15568.

[43] Mbiene JP, Mistretta CM. Initial innervation of embryonic rat tongue and developing taste papillae: nerves follow distinctive and spatially restricted pathways. Acta Anat (Basel) 1997; 160: 139-58.

[44] O'Rahilly R, Müller F. The early development of the hypoglossal nerve and occipital somites in staged human embryos. Am J Anat 1984; 169: 237-57.

[45] Dickson DH, Graves DA. The Ultrastructure and development of the eye. In: Hardisty MW, Potter IC, Eds. The biology of lampreys, vol. 3. London: Academic Press 1981; 43-95.

[46] Villar-Cerviño V, Abalo XM, Villar-Cheda B, et al. Presence of glutamate, glycine and $\gamma$-aminobutyric acid in the retina of the larval sea lamprey: comparative immunohistochemical study of classical neurotransmitters in larval and postmetamorphic retinas. J Comp Neurol 2006; 499: 810-27.

[47] Fritzsch B, Northcutt RG. Cranial and spinal nerve organization in amphioxus and lampreys: evidence for an ancestral craniate pattern. Acta Anat (Basel) 1993; 148: 96-109.

[48] Koyama H, Kishida R, Goris RC, Kusunoki T. Afferent and efferent projections of the VIIIth cranial nerve in the lamprey Lampetra japonica. J Comp Neurol 1989; 280: 663-71.

[49] Tahara S. Normal stages of development in the lamprey, Lampetra reissneri (Dybowski). Zool Sci 1988; 5:109-18.

(c) Barreiro-Iglesias et al.; Licensee Bentham Open.

This is an open access article licensed under the terms of the Creative Commons Attribution Non-Commercial License (http://creativecommons.org/licenses/by-nc/3.0/) which permits unrestricted, non-commercial use, distribution and reproduction in any medium, provided the work is properly cited. 